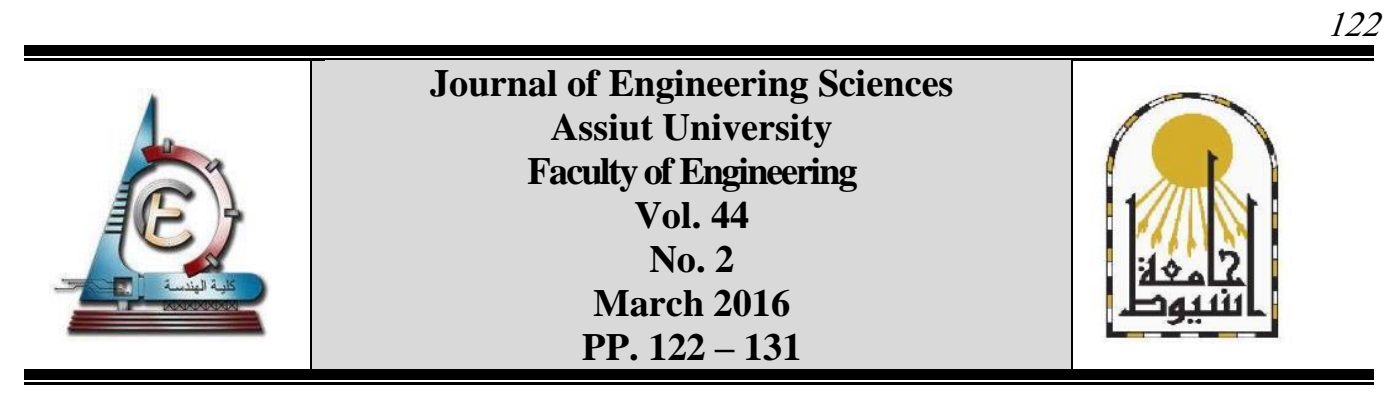

\title{
STABILIZATION OF EXPANSIVE SUBGRADE SOIL BY USING ADDITIVES
}

\author{
Mostafa Deep Hashem ${ }^{1}$, Afaf Abdel Haleem Mahmoud ${ }^{2}$, \\ Ahmed Moussa Abu Bakr ${ }^{3}$, Ahmed Awad Hag 4, * \\ 1, 2, 3 Civil Engineering Dept., Faculty of Engineering, Minia University \\ ${ }^{4}$ Civil engineer, Ministry of Water Resources and Irrigation
}

Received 16 January 2016; Accepted 1 March 2016

\begin{abstract}
Expansive soils refers to a particular type of soils - almost clayey soils - that expand as they absorb water and shrink when they dry out. The process of swelling generates pressures that can cause lifting, or heaving of structures whilst shrinkage process can cause differential settlement. A large number of buildings and roads are placed on such soil and exposed to the danger from this swelling and shrinkage processes. In order to avoid the previous mentioned risk from the expansive soil, a technique of soil stabilization should be made for this type of soil to enhance some of its properties. In this study, we experimentally treated a particular type of an expansive soil as a subgrade material by adding three different types of chemical additives which are (Addicrete P), (Addibond 65) and (Glass Fibers) at different mixing ratios 2, 4, 6\% to maintain an enhanced subgrade layer according to its swelling and bearing behavior. A series of laboratory-coded tests were conducted on the native soil. Tests are Atterberge limits, Modified proctor, and California bearing ratio test. The same tests are also conducted on each soil-additive mixed sample. Results showed that there is a tendency from the soil to stabilize by these additives. California bearing ratio was increased from $4.7 \%$ to $8.05 \%$ and the expansion after the 96 hours soaking time was eliminated from 4.95 millimeters to 0.35 millimeter. This is considered the best effect and was a result from mixing the native soil with a percent of $6 \%$ Addicrete $P$.
\end{abstract}

Keywords: Addicrete P, Addibond 65, Glass Fibers, Expansive soil, Soil stabilization.

\section{Introduction}

Subgrade is the native material underneath a constructed road or pavement. It is the foundation of the pavement structure and called formation level. Subgrade function is to prevent excessive rutting and shoving during construction, Provide good support for placement and compaction of pavement layers, limit pavement rebound deflections to acceptable limits and restrict the development of excessive permanent deformation (rutting) in the road structure during its service life. The quality of the subgrade will greatly influence the pavement design, performance and its service life. Roads constructed

\footnotetext{
* Corresponding author.

E-mail address: ahmedawadhag@yahoo.com
} 
on expansive soils areas are known for bad condition and unpredictable behavior for which the nature of the soil contributes to some extent [1].

Although water-absorbing minerals are found in the structure of most soil types, expansive soil has those with a high-concentration like montmorillonite, beidellite, smectite, bentonite, nontronite, vermiculite, attapulgite, illite and chlorite that are particularly at risk [2]. The danger from expansive soil is from that the swelling and shrinkage are not fully reversible processes. The process of shrinkage causes cracks, which on re-wetting, do not close-up perfectly and hence cause the soil to bulk-out slightly, and also allow enhanced access to water for the swelling process. In geological time scales shrinkage cracks may become in-filled with sediment, thus imparting heterogeneity to the soil. When material falls into cracks, the soil is unable to move back, thus resulting in enhanced swelling pressures [3].

The failures of pavement, in form of heave, depression, cracking and unevenness are most likely to happen by the expansive soil in the subgrade [1]. To eliminate the danger from such these soils, a technique of soil stabilization needs to be taken out. Soil stabilization is a collective term for any physical, chemical, or biological method or any combination of such methods employed to improve or change certain properties of natural soil to make it serve adequately an intended engineering purpose [4]. There are many techniques of soil stabilization like mechanical, chemical and physical stabilization. Stabilization waterproofs the soil [5], improves its strength, workability and durability and helps to reduce its volume change due to temperature or moisture.

Many researchers have investigated the possibility of stabilizing soils by adding additives. Leema Peter et al. [6] show that the addition of coir pith and short coir fiber effectively controls the shrinkage characteristics of expansive soil. Ajay Kumar et al. [7] design a mix to improve the bearing capacity of soil by using fly ash and lime mixture, reinforced with waste synthetic bag pieces and the results show that the maximum value of CBR was found to be $23.82 \%$ for $2.5 \mathrm{~mm}$ penetration and $22.21 \%$ for $5 \mathrm{~mm}$ penetration, when waste synthetic bag pieces of size $2 \mathrm{~cm} \times 2 \mathrm{~cm}$ were used at a proportion of $0.1 \%$. G. Muthumari h et al. [8] study the effects of Cement Kiln Dust and Ceramic Dust on expansive soil. It was found from the test results that L.L., P.I., O.M.C. and F.S.I. were decreased with an increment of Cement Kiln Dust (CKD) and Ceramic Dust percentage. Plastic Limit (PL), Maximum dry density (MDD), Unconfined Compressive Strength (UCS) and California Bearing Ratio (CBR) were increased with an increment of CKD and Ceramic Dust percentage. Abd El Megeed Kabasy 2013 [9] added the hay of wheat to a type of clayey swelling soil with a ratio of $0.5 \%, 1 \%$ and $1.5 \%$ by weight of the soil to improve and stabilize its characteristics. The results showed that the shear strength increases with the increase of hay ratio till approximately $1 \%$ hay addition. The indirect tensile strength for air-dried samples increased as well. The deformation due to the swelling potential also decreased to about $20 \%$. Y.I.Murthy [10] deal with the evaluation of the mechanical properties of black cotton soil mixed with mill scale in varying proportions and he concluded that mixing mill scale in varying proportions increases the permeability of the soil, strength characteristics and decreases the plasticity. Mir Sohail Ali et al. [11] investigate the effect of stone dust \& fly ash combine at different percentage on expansive soil. It was observed that at the optimum percentages, the swelling of expansive clay is almost controlled and noticed that there is a marked improvement in the other properties of soil. Mohammed Y. Fattah et al. [12] treated the expansive soil by using gasoline fuel. The results show that a percentage of $4 \%$ gasoline oil mixed with the soil is 
sufficient for better improvements for the soil. Erdal Cokca et al. [13] used granulated blast furnace slag (GBFS) and GBFS-cement (GBFSC) to overcome or to limit the expansion of an artificially prepared expansive soil sample. GBFS and GBFSC caused a successfully decreasing in the total amount of swell while an increasing in the rate of swell was happened. Nurhayat Degirmenci et al. [14] studied the application of phosphogypsum with cement and fly ash for soil stabilization. They concluded that the treatment with cement, fly ash and phosphogypsum generally reduces the plasticity index. The maximum dry unit weights increase as cement and phosphogypsum contents increase, but decrease as fly ash content increases. V. Ramana Murty et al. [15] study the efficacy of calcium chloride $(\mathrm{CaCl} 2)$, a strong electrolyte, on the plasticity and swell characteristics of an expansive clay soil and compare the influence of $\mathrm{CaCl} 2$ with The influence of lime on the properties of the clay bed. The influence of lime is brought out by using data from a previous study of lime piles on an adjacent site. It is revealed that the modification of clay properties with calcium chloride is several times greater than that for the conventionally used lime.

\section{Materials and experimental tests}

\subsection{Materials}

\subsubsection{Natural soil}

In order to have a natural expansive soil, we have brought a 250 kilograms expansive soil from Kharga Oasis - New Valley Governorate from a depth of 5 meters. New Valley Governorate is characterized by the presence of expansive soils with a high expansion value. Table 1, shows the properties of the nature soil.

Table 1.

Properties of natural soil

\begin{tabular}{|c|c|}
\hline Depth taken from & $5 \mathrm{~m}$ \\
\hline Color & Tend to red \\
\hline Liquid limit (\%) & 57.5 \\
\hline Plastic limit (\%) & 29.18 \\
\hline Plasticity index (\%) & 28.32 \\
\hline Shrinkage limit (\%) & 10.55 \\
\hline Optimum water content (\%) & 19.5 \\
\hline Maximum dry density $\left(\mathrm{gm} / \mathrm{cm}^{3}\right)$ & 1.749 \\
\hline Free Swelling (\%) & 136.36 \\
\hline California bearing ratio (Unsoaked) $(\%)$ & 27.73 \\
\hline California bearing ratio (Soaked) $(\%)$ & 4.7 \\
\hline Expansion during California bearing ratio test (millimeter) & 4.95 \\
\hline
\end{tabular}

\subsubsection{Addicrete $P$}

Addicrete $\mathrm{p}$ is the first additive added to the soil in this research. Addicrete $\mathrm{P}$ is a chemical material that based on polymerized resins. It is free from calcium chloride and similar salts, and initially is an admixture to sand-cement mortar mixes to improve workability and replaces lime in plastering and bricklaying mortars. The density of Addicrete $\mathrm{P}$ is $(1.01 \pm 0.01)$ kilogram/litre.

\subsubsection{Addibond 65}

Addibond 65 is the second additive added to the soil. Addibond 65 is a latex dispersion admixture based on styrene butadiene rubber and is used for improving the properties of cement mortar and concrete. The density of Addibond 65 is $(1.02 \pm 0.02)$ kilogram/litre. 


\subsubsection{Glass fibers}

Glass fibers are the last additive added to the soil. The glass which used was E-Glass type and the fiberglass type was chopped strands. The chop length of glass fibers is 13 millimeters and filament diameter is $(3,6,12)$ micron.

\subsection{Experimental tests}

The natural soil was mixed with each additive individually by a different mixing ratio. Three additive ratio were used $(2,4,6 \%)$ by dry weight of the soil. Several tests were conducted on the natural soil to determine its properties. Tests are free swelling, Atterberge limits, modified proctor and California bearing ratio test. For California bearing ratio test, we conduct this test twice for the natural soil (soaked and unsoaked) to observe the effect of water on the expansive soil strength. These tests were also conducted on the different soil samples of natural soil when mixed with the additives to observe the effect of these additives on the soil properties except the free swelling and un-soaked California bearing ratio test, which were conducted on the natural soil only. All tests procedure and precautions are according to the Egyptian code of soil mechanics.

\section{Experimental results and discussion}

\subsection{Free swelling test}

The free swelling of the natural soil was measured and found to be $136.36 \%$.

\subsection{Effect of additives on liquid limit}

The relationships between additives content and liquid limit are illustrated in Fig. (1) for all types of additives. It is clear from the results that the liquid limit decreased with the increase of additive content for all types of additives. The massive decreasing was obviously observed when Addicrete $\mathrm{P}$ was added to the soil but the other two additives has no remarkable effect.

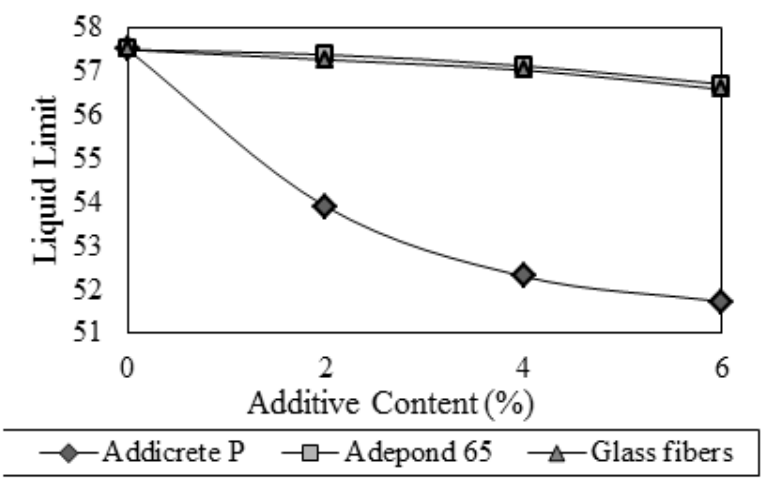

Fig. 1. Effect of additives on liquid limit

\subsection{Effect of additives on plastic limit}

Figure (2) shows the relationships between additives content and plastic limit for all types of additives. It is clear from the results that the plastic limit increased with the increase of additive content for all types of additives. This result occurs for case of using Addicrete $\mathrm{P}$ additive followed by Addibond 65. The effect of Glass Fibers additive on plastic limit values was unnoticeable and precarious. The remarkable increasing is also resulted from Addicrete $\mathrm{P}$ additive followed by the increasing resulted from the Addibond 65 additive. 


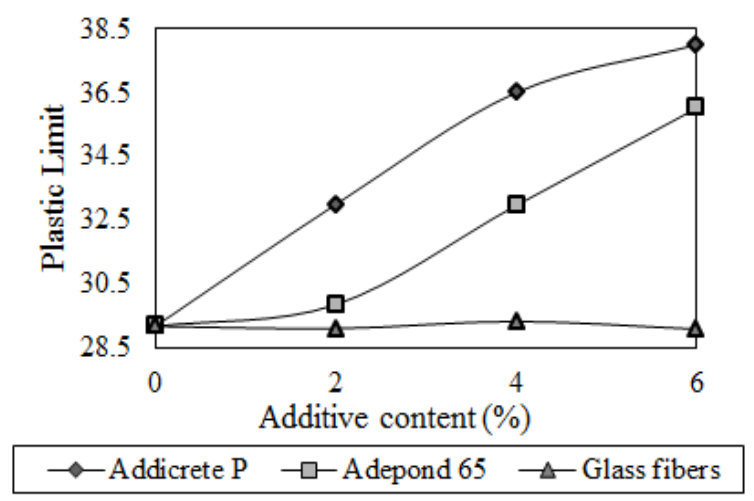

Fig. 2. Effect of additives on plastic limit

\subsection{Effect of additives on shrinkage limit}

Effect of additives content on shrinkage limit is illustrated in Fig. (3). It is clear from the results that the shrinkage limit increased with the increase of additive content for all types of additives. This result occurs for case of using Addicrete $\mathrm{P}$ additive followed by Addibond 65. As before, Addicrete P additive has the salient effect on the shrinkage limit values followed by Addibond 65 but the Glass Fibers did not satisfy the predicted results. Glass Fibers effect was unnoticeable.

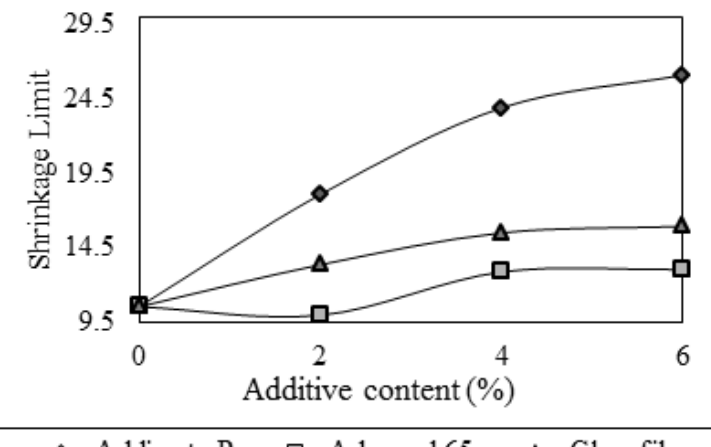

$\multimap$ Addicrete P $\neg$-Adepond $65 \rightarrow-$ Glass fibers

Fig. 3. Effect of additives on shrinkage limit

\subsection{Effect of additives on compaction properties}

Figures (4 and 5) illustrate the effect of additives content on optimum water content and maximum dry density of soil respectively for all types of additives.

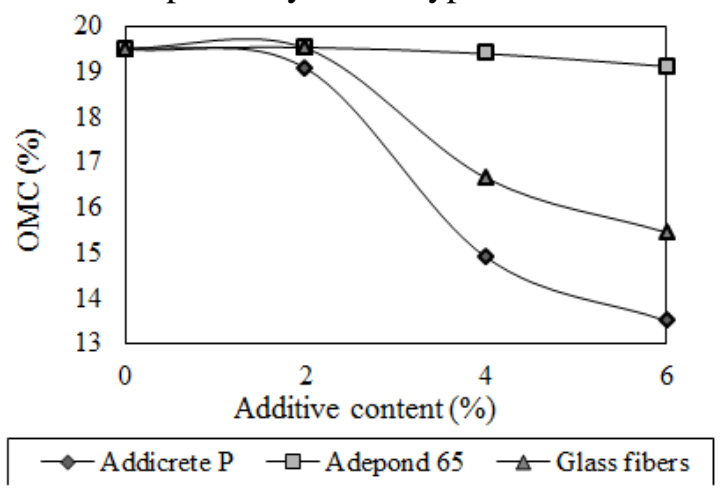

Fig. 4. Effect of additives on optimum water content 
Increasing Addicrete $\mathrm{P}$ content lead to a decreasing in optimum water content value. A percent of $2 \%$ Addibond 65 caused an increasing in the value of optimum water content but it began to decrease with the increase of the additive content. Glass Fibers additive caused an increasing in the value of optimum water content according to 2 an $4 \%$ additive content but a percent of $6 \%$ Glass Fibers additive caused a decreasing for optimum water content.

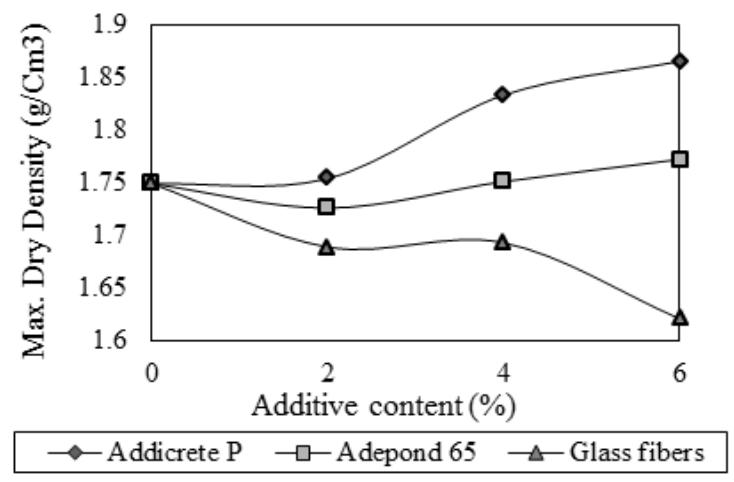

Fig. 5. Effect of additives on maximum dry density

Increasing additive content caused an increasing in maximum dry density value. This result is for case of Addicrete $\mathrm{P}$ and Addibond 65. Glass Fibers additive has unnoticeable effect on the value of maximum dry density.

\subsection{Effect of additives on California bearing ratio and expansion behavior}

Figures (6 and 7) illustrate the effect of additives on the California bearing ratio and total expansion after the 96 hours curing time values. Adding additives caused an increasing in the California bearing ratio value. Increasing additive content caused an increase in the value of California bearing ratio except the $6 \%$ Glass Fibers additive content which caused a decrease in its value.

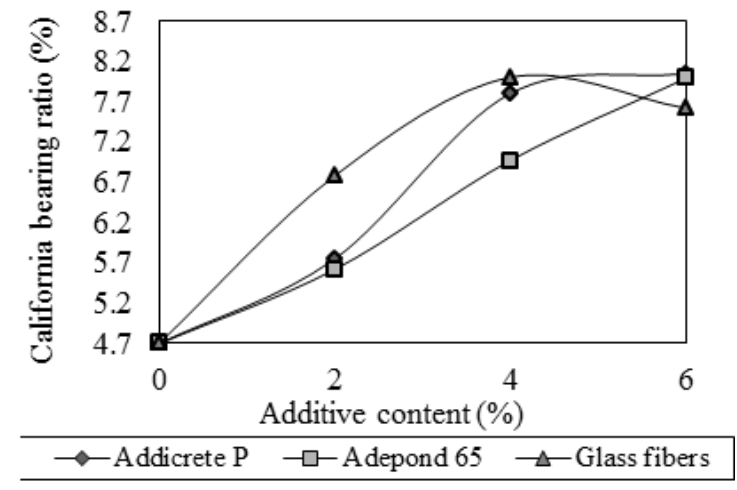

Fig. 6. Effect of additives on California bearing ratio

When natural soil mixed with additives, a great limitation occurred for the total expansion value after the curing time. The salient effect observed when natural soil mixed Addicrete P.

\subsection{Optimum effect of additives}

The optimum effect of Addicrete P, Addibond 65 and Glass Fibers on each property of the soil are shown in Figures 8, 9 and 10 respectively. When column is above zero-line, the property numerical value is in increase and when column is under zero-line, the property numerical value is in decrease. 


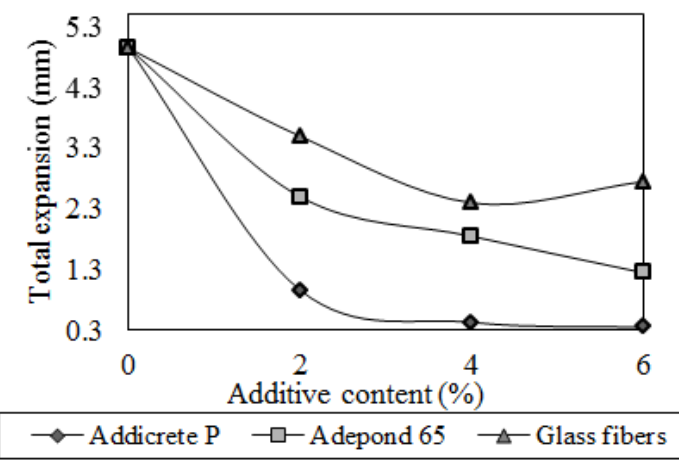

Fig. 7. Effect of additives on total expansion after the 96 hours curing time

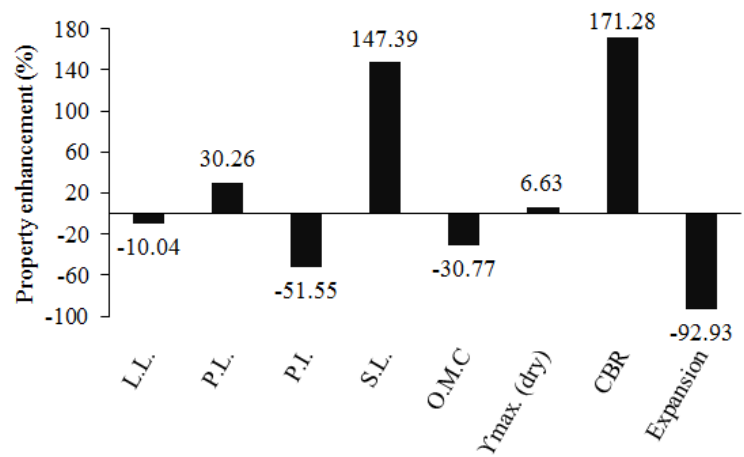

Fig. 8. Optimum effect of Addicrete $\mathrm{P}$ on soil properties

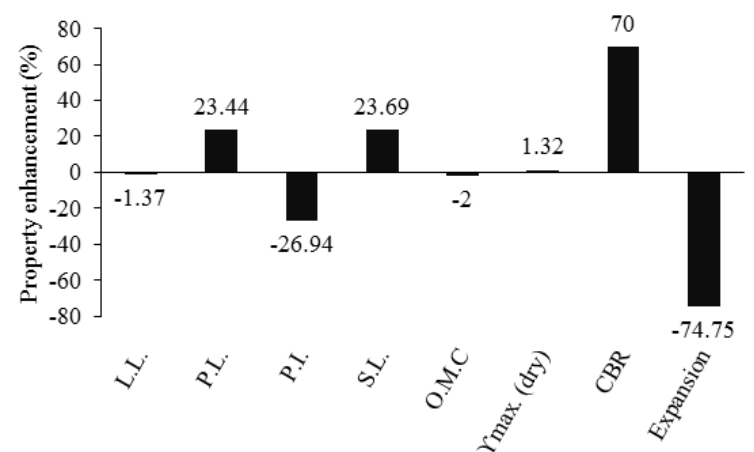

Fig. 9. Optimum effect of Addibond 65 on soil properties

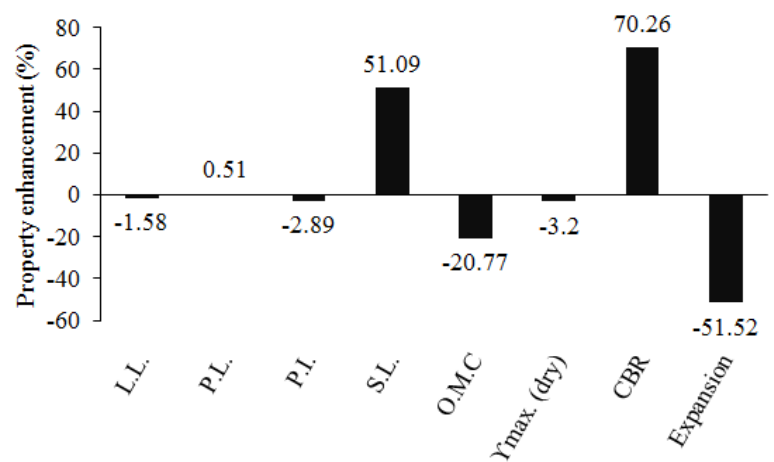

Fig. 10. Optimum effect of Glass Fibers on soil properties 
For California bearing ratio, the percentage increase in its values due to using different additives are $171.28 \%, 70 \%, 70.26 \%$ for Addicrete P, Addibond 65 and glass fibers, respectively.

For maximum dry density, the percentage increase in its values are $6.63 \%$ and $1.32 \%$ for Addicrete $\mathrm{P}$ and Addibond 65, respectively. Otherwise, for glass fibers maximum dry density decreased by $3.20 \%$.

For expansion values, The percentage decrease in it are $92.93 \%, 74.75 \%$ and $51.52 \%$ for Addicrete P, Addibond 65 and glass fibers, respectively.

\section{Conclusion}

Based on the results and analysis had been done for this research, the following conclusions are drawn.

1- Adding additives to natural expansive soil help to enhance soil properties.

2- Addicrete $\mathrm{P}$ has the salient effect on the soil compared by Addibond 65 and Glass Fibers.

3- Mixing the natural soil with Addicrete $\mathrm{P}$ increased the California bearing ratio from $4.70 \%$ to $8.05 \%$ and eliminated the total expansion of the soil after 96 hours soaking time by $92.93 \%$. It increased also the maximum dry density by $6.63 \%$. Plasticity index decreased from $28.32 \%$ to $13.72 \%$ and shrinkage limit increased from $10.55 \%$ to $26.10 \%$.

4- Adding Addibond 65 also enhanced the soil properties but not as the remarkable effect caused by the adding of Addicrete P. California bearing ratio increased by $70 \%$ and the expansion after the curing time was eliminated by $74.75 \%$. Maximum dry density increased by $1.32 \%$. Plasticity index was reduced from $28.32 \%$ to $20.69 \%$ and shrinkage limit increased from $10.55 \%$ to $13.05 \%$.

5- Adding Glass Fibers to natural soil showed the best effect on California bearing ratio value which increased by $70.26 \%$. Total expansion after the curing time was eliminated from $4.95 \mathrm{~mm}$ to $2.40 \mathrm{~mm}$. Maximum dry density decreased by $3.20 \%$. Plasticity index was reduced from $28.32 \%$ to $27.50 \%$ and shrinkage limit increased from $10.55 \%$ to $15.94 \%$.

6- Overview of the effect of additives on soil properties, Addicrete $\mathrm{P}$ has the best effect on soil properties compared with Addibond 65 and Glass Fibers.

\section{REFERENCES}

[1] Magdi M. E. Zumrawi, "Pavement Design for Roads on Expansive Clay Subgrades", UofKEJ, Vol.3, Issue 1, pages52-58, 2013.

[2] Home Inspection Engineers, Inc. - one of the oldest, most established home inspection firms in Colorado, “Here's What Expansive Soil Problems Look Like “,June 15, 2015.

[3] Holtz and Kovacs, "An introduction to geotechnical engineering", Prentice-Hall, New Jersey, 1981.

[4] Hans F. Winterkorn and Sibel Pamukcu, "Soil Stabilization and Grouting", Foundation Engineering Handbook, pages 317-378, 1991.

[5] S.S Razvi, Shaikh Mustaqueem Ahmed and Syed Rehan Ahmed, "STUDY ON STABILIZATION OF SOIL USING RBI GRADE 81", International Journal of Innovative Research in Advanced Engineering (IJIRAE), Issue 5, Volume 2, May 2015.

[6]Leema Peter, K. K. Nisha, P. K. Jayasree and K. Balan, "Shrinkage Characteristics of Expansive Soil Treated with Coir Waste", Indian Geotechnical Journal, Volume 45, Issue 3, pp. 360-367, September 2015.

[7] Ajay Kumar Agarwal, Vaishali Rajurkar and Prerna Mokadam, "Effect of waste synthetic 
bag pieces on the CBR value of expansive Soil", Journal of Materials and Engineering Structures « JMES », Vol. 2, No 1, 2015.

[8] G. Muthumari, R. Nasar Ali and J. Dhaveethu Raja, "Comparative Study on Stabilization of Expansive Soil using Cement Kiln Dust and Ceramic Dust", Journal of Geotechnical Engineering, Vol. 1, No. 3, 2014.

[9] Abd El Megeed Kabasy Mohamed, "Improvement of swelling clay properties using hay fibers", Construction and Building Materials Journal, Volume 38, Pages 242-247, 2013.

[10] Y.I.Murthy, "Stabilization of expansive soil using mill scale", International Journal of Engineering Science and Technology, 2012.

[11] Mir Sohail Ali and Shubhada Sunil Koranne, "Performance Analysis of Expansive Soil Treated With Stone Dust and Fly Ash", The Electronic Journal of Geotechnical Engineering, Volume 16, 2011.

[12] Mohammed Y. Fattah, Firas A. Salman and Bestun J. Nareeman, "A treatment of expansive soil using different additives", Acta Montanistica Slovaca -international scientific journal, Volume 15, Issue 4, pages 290-297, 2010.

[13] Erdal Cokca, Veysel Yazici and Vehbi Ozaydin, "Stabilization of Expansive Clays Using Granulated Blast Furnace Slag (GBFS) and GBFS-Cement", Geotechnical and Geological Engineering Journal, Volume 27, Issue 4, pages 489-499, 2009.

[14] Nurhayat Degirmenci, Arzu Okucub and Ayse Turabi, "Application of phosphogypsum in soil stabilization“, Building and Environment journal, Volume 42, Issue 9, Pages 3393-3398, September 2007.

[15] V. Ramana Murty, and P. Hari Krishna, "Stabilization of expansive clay bed using calcium chloride solution“, Proceedings of the Institution of Civil Engineers - Ground Improvement, Volume 10 Issue 1, pages 39-46, January 2006. 


\section{تثبيت تربة التأسيس الاتتفاثية للطرق باستخدام الاضافات}

الملخص العربي:

التربة الانتفاثية هي التربة التي تحتوي على المعادن الممتصة للماء و التي تسبب في حدوث زيادة لحجم

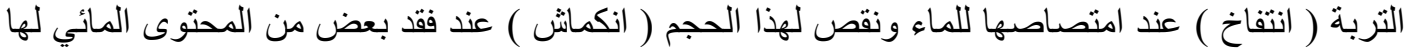

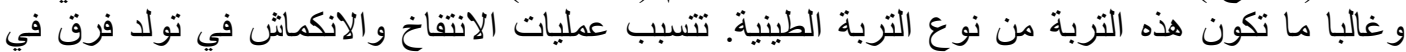

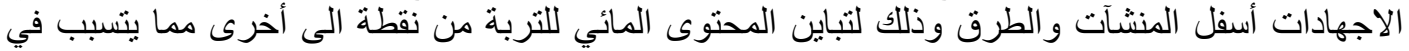

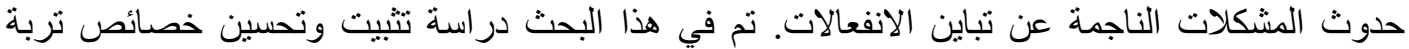

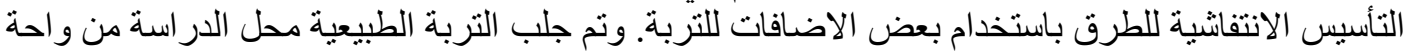

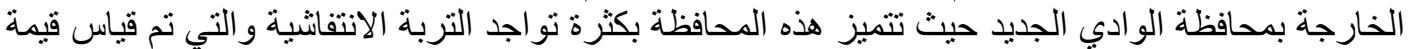

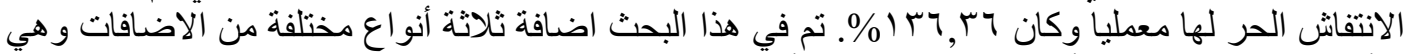

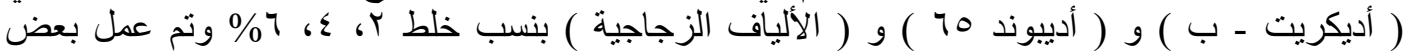

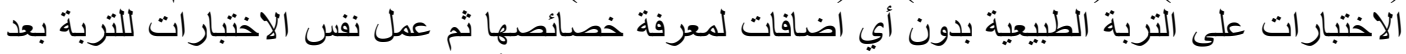

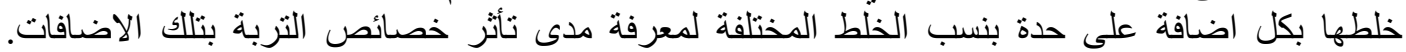

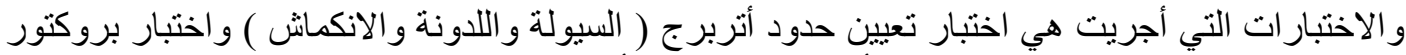

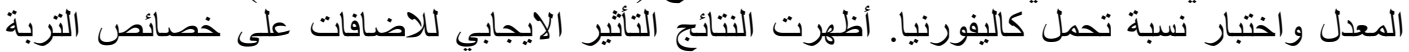

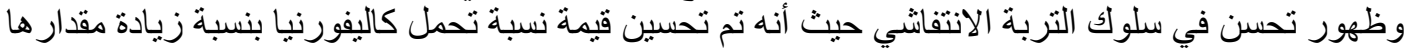

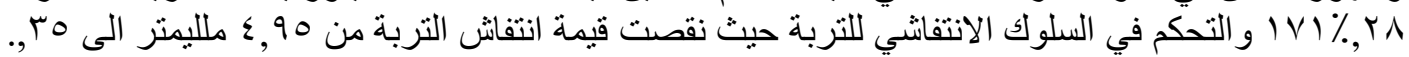

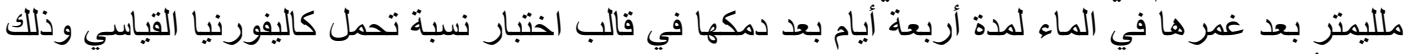

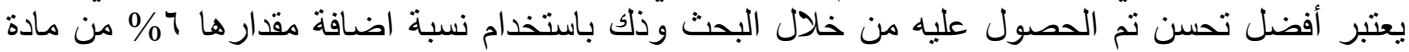

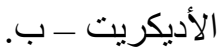

